\title{
PReS-FINAL-2243: Reduced volumetric trabecular bone mineral density in children with idiopathic hypercalciuria. A peripheral quantitative computed tomography (PQCT) study (preliminary results)
}

E Atsali , KD Stathopoulos, I Bournazos, P Nicolaidou, P Papaggelopoulos, G Skarantavos

From 20th Pediatric Rheumatology European Society (PReS) Congress

Ljubljana, Slovenia. 25-29 September 2013

\section{Introduction}

Idiopathic hypercalciuria (IH) is defined as excessive $24 \mathrm{~h}$ urinary calcium excretion $(>4 \mathrm{mg} / \mathrm{kg} / 24 \mathrm{~h}$ ), that persists after correction of dietary imbalances, in the absence of secondary causes. Decreased areal BMD in children with IH has been reported in recent studies with DXA.

\section{Objectives}

We used peripheral Quantitative Computed Tomography ( $\mathrm{pQCT}$ ) of the tibia in order to test the hypothesis that $\mathrm{IH}$ results in decreased volumetric $\left(\mathrm{mg} / \mathrm{cm}^{3}\right) \mathrm{BMD}$ of trabecular and/or cortical compartment of bone.

\section{Methods}

We studied 14 children ( 8 boys- 6 girls, aged $6-18$ years) with newly discovered $\mathrm{IH}$ who were admitted to our clinic. Most of them presented with either hematuria or recurrent abdominal or lumbar pain. After establishment of the diagnosis, all children underwent DXA of the lumbar spine. We also performed $\mathrm{PQCT}$ of the tibia (Stratec XCT-2000 scanner), 4 slices were obtained at the $4 \%, 14 \%, 38 \%$ and $66 \%$ of tibia length sites. For the $4 \%$ slice, we assessed variables of trabecular bone and especially trabecular BMD (TRAB_DEN, $\mathrm{mg} / \mathrm{cm}^{3}$ ). For $14 \%$ we assessed parameters of subcortical bone and for the $38 \%$ and $66 \%$ sites parameters of cortical bone. pQCT data of the children with IH were compared to those of healthy race-, age- and sex-matched children from the published pQCT database of Moyer-Miller et al (J Clin Densitom, 2008) who used the same pQCT device, software and site measurements as we did.

\section{Results}

$7 / 14$ children with IH (50\%) were found to have z-scores $<-1$ SD in the DXA measurements of the lumbar spine. For the pQCT measurements, we report here only the preliminary results of trabecular BMD (ongoing analysis): 8/14 children with IH (57\%) had reduced volumetric bone mineral density (TRAB_DEN < $2 \mathrm{SD}$ ) when compared with healthy children of the same age, race, sex and height of the Moyer-Miller study.

\section{Conclusion}

Our study provides preliminary evidence of reduced trabecular bone mineral density in children with $\mathrm{IH}$ as compared to healthy ones.

\section{Disclosure of interest}

None declared.

Published: 5 December 2013

doi:10.1186/1546-0096-11-S2-P233

Cite this article as: Atsali et al:: PReS-FINAL-2243: Reduced volumetric trabecular bone mineral density in children with idiopathic

hypercalciuria. A peripheral quantitative computed tomography (PQCT) study (preliminary results). Pediatric Rheumatology 2013 11(Suppl 2):P233.

"Attikon" University Hospital, Haidari - Athens, Greece 